\title{
Nanog inhibits lipopolysaccharide-induced expression of pro-inflammatory cytokines by blocking NF-кB transcriptional activity in rat primary microglial cells
}

\author{
HAITAO ZHOU ${ }^{1,2}$, SHIYAN CHEN $^{1}$, WEI WANG ${ }^{1}$, ZHIQIANG WANG $^{1}$, XIULI WU $^{2}$ and ZHIJIAN ZHANG ${ }^{1,2}$ \\ ${ }^{1}$ Neurology Department, The First Affiliated Hospital of Fujian Medical University; \\ ${ }^{2}$ Fujian Institute of Neurology, Fujian Medical University, Fuzhou, P.R. China
}

Received September 10, 2011; Accepted December 14, 2011

DOI: $10.3892 / \mathrm{mmr} .2011 .719$

\begin{abstract}
Nanog is an essential transcription factor maintaining the self-renewal and pluripotency of embryonic stem cells, which binds to nuclear factor- $\kappa \mathrm{B}(\mathrm{NF}-\kappa \mathrm{B})$ proteins, inhibits their transcriptional activity and represses their prodifferentiation activity. The persistent and excessive activation of microglial cells, as primary immune cells in the central nervous system is associated with various nerve system diseases, such as neuropathic pain, ischemia, infection, as well as neurodegenerative diseases. However, the effects of Nanog on the activation of microglial cells have yet to be elucidated. In this study, we investigated whether Nanog inhibits the production of pro-inflammatory factors in lipopolysaccharide (LPS)-stimulated microglial cells. Nanog was shown to downregulate the mRNA and protein levels of IL-1 $\beta$, TNF- $\alpha$ and IL- 6 in LPS-stimulated rat primary microglial cells. Furthermore, we also found that the transcriptional activity of $N F-\kappa B$ was dramatically reduced by Nanog, which was measured using luciferase assay. The results suggest that Nanog reduces the production of pro-inflammatory cytokines and attenuates inflammatory responses in LPS-stimulated microglial cells by blocking the transcriptional activity of NF- $\kappa$ B. Thus, Nanog may be a potentially useful anti-inflammatory therapy for the treatment of various nervous system diseases.
\end{abstract}

\section{Introduction}

Microglial cells are resident central nervous system (CNS) cells that sense pathological tissue alterations, develop into macrophages and perform immunological functions (1). Activation of microglia and inflammation-mediated neurotoxicity are suggested to play a decisive role in the pathogenesis of various

Correspondence to: Dr Zhijian Zhang, Neurology Department, The First Affiliated Hospital of Fujian Medical University, No. 20 Chazhong Road, Fuzhou 350005, P.R. China

E-mail: zjzhangfjmu@gmail.com

Key words: Nanog, microglia, NF-кB, cytokine, inflammation neurological disorders, such as ischemia, neuropathic pain, trauma, as well as neurodegenerative diseases (2). Activated microglial cells release pro-inflammatory factors, such as IL-1 $\beta$, TNF- $\alpha$ and IL-6, which contribute to neuronal damage. Thus, development of targeted anti-inflammatory therapies is essential to delay or stop the progression of neurological disease (3).

Nanog, which maintains embryonic stem (ES) cell selfrenewal independently of LIF/Stat3, is a critical transcription factor underlying pluripotency in both inner cell mass (ICM) and ES cells (4). Nanog mRNA is present in pluripotent mouse and human cell lines, and is absent in differentiated cells (5). Additionally, Nanog choreographs the synthesis of the naive epiblast ground state in the embryo and this function is recapitulated in the culmination of somatic cell reprogramming $(6,7)$. Furthermore, research has shown that Nanog binds to nuclear factor- $\kappa \mathrm{B}(\mathrm{NF}-\kappa \mathrm{B})$ proteins, inhibits their transcriptional activity and represses the pro-differentiation activities of $\mathrm{NF}-\kappa \mathrm{B}(8)$.

$N F-\kappa B$ is involved in many biological processes, such as development, apoptosis and anti-apoptosis, innate immunity and inflammation (9). However, there is no evidence regarding the association between Nanog and $\mathrm{NF}-\kappa \mathrm{B}$ in inflammation. We hypothesize that Nanog inhibits the transcriptional activity of $\mathrm{NF}-\kappa \mathrm{B}$ and reduces the expression of pro-inflammatory cytokines in inflammatory conditions, which may be a useful anti-inflammatory therapy for various nervous system diseases.

\section{Materials and methods}

Reagents. Dulbecco's modified Eagle's medium (DMEM), fetal bovine serum (FBS), TRIzol reagent and Lipofectamine 2000 were purchased from Invitrogen Corporation (Carlsbad, CA, USA). Lipopolysaccharide (LPS), dimethyl sulfoxide (DMSO) and MTT were obtained from Sigma (St. Louis, MO, USA). $\mathrm{NF}-\kappa \mathrm{B}$ responsive luciferase plasmid and Renilla luciferase reporter plasmid, $\mathrm{pNF}-\kappa \mathrm{B}-\mathrm{luc}$ and $\mathrm{pRL}-\mathrm{TK}$, were purchased from Promega (Madison, WI, USA). Conventional restriction enzyme for BamHI and SalI, T4 DNA ligase, the First Strand cDNA Synthesis kit and the PCR Master Mix were obtained from Fermentas (Hanover, MD, USA). ELISA kits specific to rat IL-1 $\beta$, TNF- $\alpha$ and IL- 6 were purchased from R\&D 
Systems (Minneapolis, MN, USA). Penicillin-streptomycin solution, the dual luciferase reporter gene assay kit, DNA gel extraction kit, pUCm-T vector and eukaryotic expression vector pCMV-Blank were obtained from Beyotime (Shanghai, China). Cloning plasmid pUC57-Nanog was purchased from Yingrun (Changsha, China).

Plasmid construction. The coding sequence of Nanog was subcloned from pUC57-Nanog with a specific primer having a restriction enzyme site $($ BamHI/SalI) at the end. The reaction solution was electrophoresed, and the target DNA fragment was collected using a DNA gel extraction kit. It was then linked with the pUCm-T vector in the presence of T4 DNA ligase. The correct recombinant was screened and amplified. After double digestion (BamHI/SalI) of the recombinant, the reaction solution was managed as above. The eukaryotic expression vector pCMV-Blank also underwent a double digestion $(\mathrm{BamHI} / \mathrm{SalI})$, and the reaction solution was managed as above. The target DNA fragment was then linked with linear pCMV-Blank vector in the presence of T4 DNA ligase. The correct recombinant, pCMV-Nanog, was screened, amplified and stored at $-20^{\circ} \mathrm{C}$.

Cell culture. The primary microglial cells were prepared from cerebral cortex of 2-3 post-natal day Sprague-Dawley rat pups as previously described $(10,11)$ with modification. Briefly, the cortical tissue was minced with a sterile scalpel blade and digested with trypsin/EDTA for $15 \mathrm{~min}$ at $37^{\circ} \mathrm{C}$ followed by addition of DMEM supplemented with 10\% FBS and $1 \%$ penicillin-streptomycin solution to end digestion. The mixture was blended with a 5-ml pipette several times and filtrated with 200 nylon mesh. It was then centrifuged at $1,000 \mathrm{rpm}$ for $10 \mathrm{~min}$. After the supernatant was discarded, the cells were suspended in media and maintained at $37^{\circ} \mathrm{C}$ in a humidified atmosphere containing $5 \% \mathrm{CO}_{2}$. Media were changed every 3-4 days. After 8 days in vitro, the flasks were shaken at $37^{\circ} \mathrm{C}$ in a constant-temperature shaking incubator at $200 \mathrm{rpm}$ for $4 \mathrm{~h}$. The media containing microglia were removed and centrifuged at $1,000 \mathrm{rpm}$ for $10 \mathrm{~min}$. After the supernatant was discarded, the cells were suspended in media and maintained at $37^{\circ} \mathrm{C}$ in a humidified atmosphere containing $5 \% \mathrm{CO}_{2}$. Cells were found to consist of $98 \%$ microglia by staining with the OX-42 antibody (Santa Cruz).

Cell viability assay. Microglial cells were plated at a density of $5 \times 10^{3}$ cells/well in 96-well plates the day before transfection. After overnight incubation, cells were transfected with different concentrations of pCMV-Nanog $(0,1.0,2.0$ and $3.0 \mu \mathrm{g} / \mathrm{ml}$ ) using Lipofectamine 2000 for $24 \mathrm{~h}$, according to the manufacturer's instructions. The cells were then stimulated with LPS $(100 \mathrm{ng} / \mathrm{ml})$ or without for $24 \mathrm{~h}$. After treatment, $20 \mu \mathrm{l}$ of MTT $(5 \mathrm{mg} / \mathrm{ml})$ was added to each well and incubated for $4 \mathrm{~h}$ at $37^{\circ} \mathrm{C}$. The supernatant was then removed and $150 \mu \mathrm{l}$ DMSO was added to each well to dissolve the formazan crystals. After the plates were vortexed for $10 \mathrm{~min}$, the optical density (OD) value was measured with a microplate reader at $570 \mathrm{~nm}$.

Reverse transcription-polymerase chain reaction (RT-PCR). Microglial cells were plated at a density of $3 \times 10^{5}$ cells/well

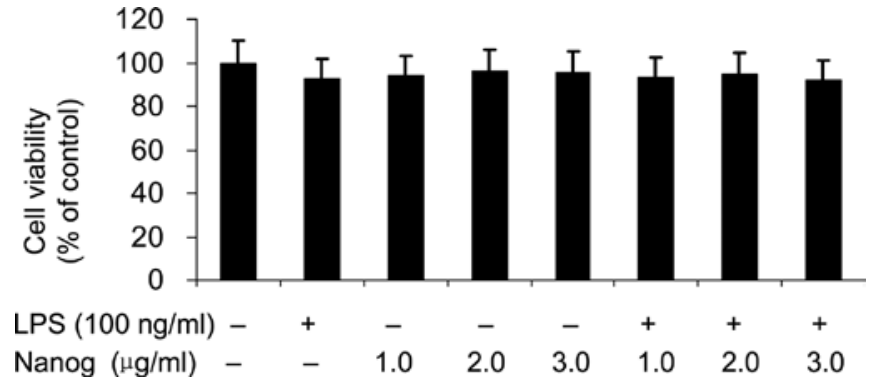

Figure 1. Effects of Nanog and LPS on the viability of microglial cells. After transfection with $0-3.0 \mu \mathrm{g} / \mathrm{ml}$ pCMV-Nanog for $24 \mathrm{~h}$, cells were stimulated with LPS $(100 \mathrm{ng} / \mathrm{ml})$ or without for $24 \mathrm{~h}$. Cell viability was then measured using MTT assay. All data are presented as the means \pm SD of three independent experiments. There was no significant difference among the groups.

in a 6-well plate the day before transfection. After overnight incubation, cells were transfected with different concentrations of pCMV-Nanog $(0,1.0,2.0$ and $3.0 \mu \mathrm{g} / \mathrm{ml})$ for $24 \mathrm{~h}$. Cells were then stimulated with LPS $(100 \mathrm{ng} / \mathrm{ml})$ for $6 \mathrm{~h}$. RT-PCR was performed with total RNA. The total RNA of cells was isolated using TRIzol reagent, according to the manufacturer's instructions. The purity and concentration of the RNA preparation were determined by measuring the absorbance ratio at $260 / 280 \mathrm{~nm}$. RT was performed using the first-strand cDNA synthesis kit according to the manufacturer's recommendations. PCR analyses were performed on the cDNA using PCR master mix. The following sense and antisense primers were used: $\beta$-actin, sense 5'-ACT GGC ATT GTG ATG GAC TC-3' and antisense 5'-CAG CAC TGT GTT GGC ATA GA-3'; Nanog, sense 5'-TCT CCT CCG CCT TCC TCT-3' and antisense 5'-TTG CCT CTG AAA CCT ATC CT-3'; IL-1 $\beta$, sense 5'-CTG TTC TTT GAG GCT GAC-3' and antisense 5'-GAT TTT GTC GTT GCT TGT-3'; TNF- $\alpha$, sense 5'-GTA GCA AAC CAC CAA GCG-3' and antisense 5'-GCA ATG ACT CCA AAG TAG ACC-3'; IL-6, sense 5'-TGC CTT CTT GGG ACT GAT-3' and antisense 5'-CTG GCT TTG TCT TTC TTG TTA T-3'. Reactions were carried out in a volume of $25 \mathrm{ml}$. PCR was performed with 35 cycles of sequential reactions: $94^{\circ} \mathrm{C}$ for $30 \mathrm{sec}, 55^{\circ} \mathrm{C}$ for $30 \mathrm{sec}$ and $72^{\circ} \mathrm{C}$ for $40 \mathrm{sec}$. The amplified products were electrophoresed with $1.5 \%$ agarose gel and viewed with UV transillumination.

ELISA. Microglial cells were plated at a density of $5 \times 10^{4}$ cells/ well in a 24-well plate the day before transfection. After incubation overnight, cells were transfected with different concentrations of pCMV-Nanog $(0,1.0,2.0$ and $3.0 \mu \mathrm{g} / \mathrm{ml})$ for $24 \mathrm{~h}$. The cells were then stimulated with LPS (100 ng/ $\mathrm{ml}$ ) for $24 \mathrm{~h}$. Cytokine levels in the culture supernatants were measured using ELISA kits specific to rat IL- $1 \beta$, TNF- $\alpha$ and IL-6 according to the manufacturer's recommendations.

Luciferase assay. Microglial cells were plated at a density of $3 \times 10^{5}$ cells/well in 6-well plates the day before transfection. After overnight incubation, cells were transfected with $0.3 \mu \mathrm{g} \mathrm{pNF}-\mathrm{kB}-\mathrm{luc}$ and $0.1 \mu \mathrm{g}$ pRL-TK using Lipofectamine, plus different concentrations of pCMV-Nanog $(0,1.0,2.0$ and $3.0 \mu \mathrm{g} / \mathrm{ml}$ ) for $24 \mathrm{~h}$. The cells were then stimulated with 

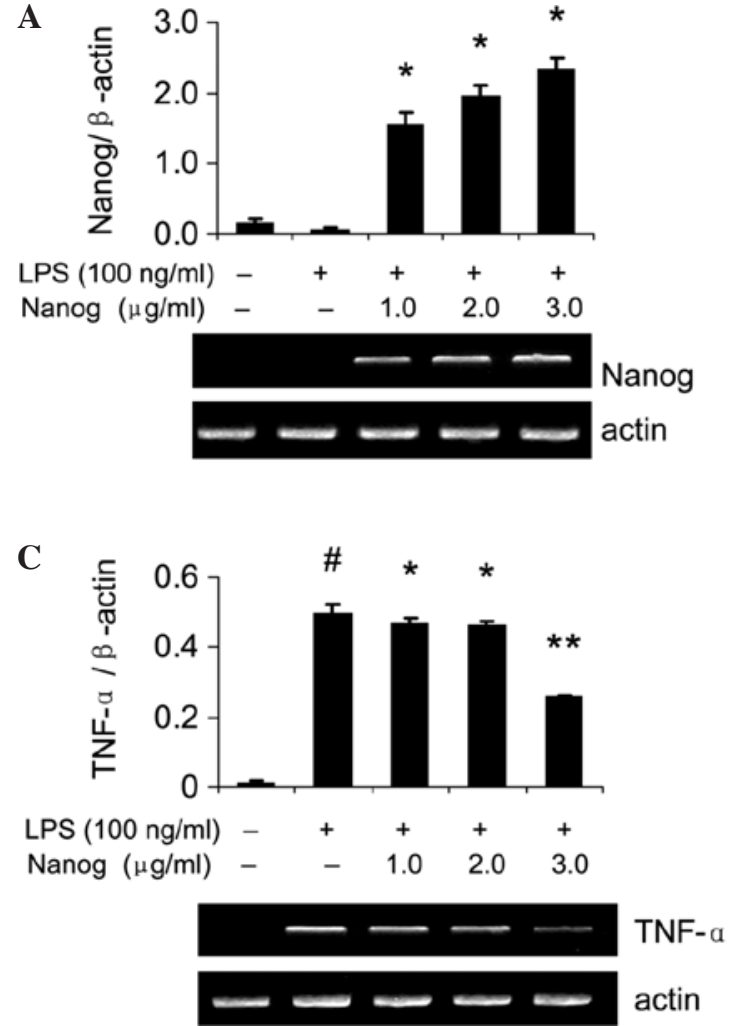

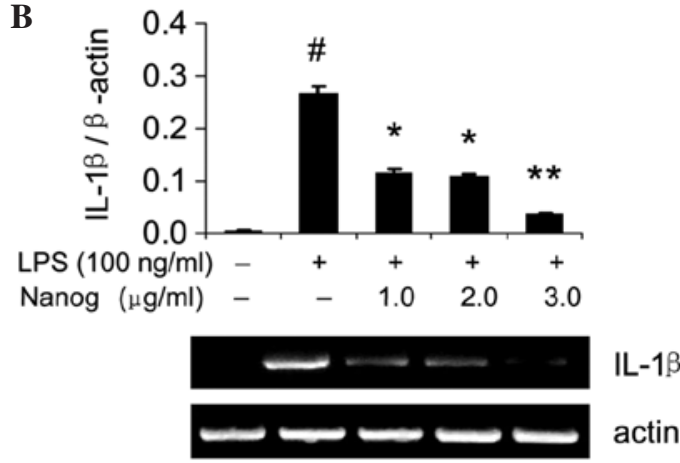

D
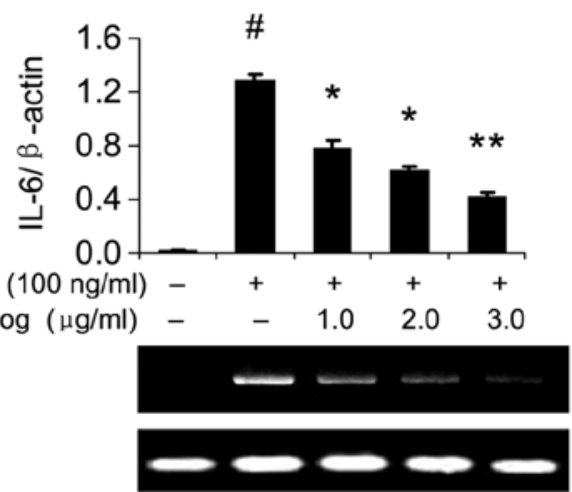

IL-6 actin

Figure 2. Effects of Nanog on the mRNA expression levels of IL-1 $\beta$, TNF- $\alpha$ and IL-6 in LPS-stimulated microglial cells. After transfection with 0-3.0 $\mu$ g/ml pCMV-Nanog for $24 \mathrm{~h}$, cells were stimulated with LPS (100 ng/ml) for $6 \mathrm{~h}$. (A) The mRNA expression level of Nanog was detected by RT-PCR. *P<0.01 vs. the untransfected group. The mRNA expression levels of (B) IL-1 $\beta,(\mathrm{C}) \mathrm{TNF}-\alpha$ and (B) IL-6 were also detected by RT-PCR. ${ }^{\#} \mathrm{P}<0.01$ vs. the control group; ${ }^{*} \mathrm{P}<0.05,{ }^{* *} \mathrm{P}<0.01$ vs. the LPS-only treated group. All data are presented as the means \pm SD of three independent experiments.

LPS (100 ng/ml) for $18 \mathrm{~h}$. Luciferase assay was performed according to the manufacturer's instructions.

Statistical analysis. All the data are expressed as the means \pm SD of three independent experiments. One-way analysis of variance (ANOVA) was used to compare the measurement data among multiple groups. $\mathrm{P}$-value $<0.05$ was considered to denote statistical significance.

\section{Results}

Effects of Nanog and LPS on the viability of microglial cells. To identify whether Nanog influences the viability of microglial cells, the cells were transfected with different concentrations of pCMV-Nanog for $24 \mathrm{~h}$ and stimulated with or without LPS for $24 \mathrm{~h}$ before the MTT assay was carried out. As shown in Fig. 1, cell viability was not significantly influenced after the transfection of pCMV-Nanog in the presence or absence of LPS. These results suggest that the viability of microglial cells is not influenced by LPS or Nanog.

Effects of Nanog on the expression of $I L-1 \beta, T N F-\alpha$ and IL-6 in LPS-stimulated microglial cells at the mRNA level. Pro-inflammatory cytokines, including IL- $1 \beta, \mathrm{TNF}-\alpha$ and IL-6, play an important role in the occurrence and development of many neurological disorders $(12,13)$. In order to examine the effects of Nanog on the production of pro-inflammatory cytokines IL-1 $\beta$, TNF- $\alpha$ and IL- 6 at the mRNA level, microglial cells were transfected with different concentrations of
pCMV-Nanog for $24 \mathrm{~h}$ and stimulated with LPS. Following $6 \mathrm{~h}$ of LPS stimulation, the expression of mRNA was detected using RT-PCR. As shown in Fig. 2, mRNA expression levels of IL-1 $\beta$, TNF- $\alpha$ and IL- 6 were markedly increased in the LPS-stimulated microglial cells. However, this tendency was significantly suppressed by Nanog in a concentration-dependent manner. Transfection with $3.0 \mu \mathrm{g} / \mathrm{ml}$ Nanog markedly inhibited the production of mRNA of IL-1 $\beta$, TNF- $\alpha$ and IL- 6 . These results suggest that Nanog alleviates inflammatory reaction in activated microglial cells at mRNA level.

Effects of Nanog on the expression of $I L-1 \beta, T N F-\alpha$ and IL-6 in LPS-stimulated microglial cells at the protein level. To investigate the effects of Nanog on the production of proinflammatory cytokines IL- $1 \beta$, TNF- $\alpha$ and IL- 6 at the protein level, microglial cells were transfected with different concentrations of pCMV-Nanog for $24 \mathrm{~h}$ and stimulated with LPS. Following $24 \mathrm{~h}$ of LPS stimulation, the production of protein in the culture medium was measured using ELISA. As shown in Fig. 3, microglial cells stimulated with LPS exhibited a distinct increase in the production of IL-1 $\beta$, TNF- $\alpha$ and IL-6. Consistent with the effect on mRNA expression levels, Nanog significantly reduced LPS-induced expression of IL- $1 \beta$, TNF- $\alpha$ and IL-6 protein in microglial cells. These results indicate that Nanog prevents inflammatory reaction in activated microglial cells at protein level.

Effects of Nanog on the transcriptional activity of $N F-\kappa B$ in LPS-stimulated microglial cells. $\mathrm{NF}-\kappa \mathrm{B}$ is a crucial 
$\mathbf{A}$

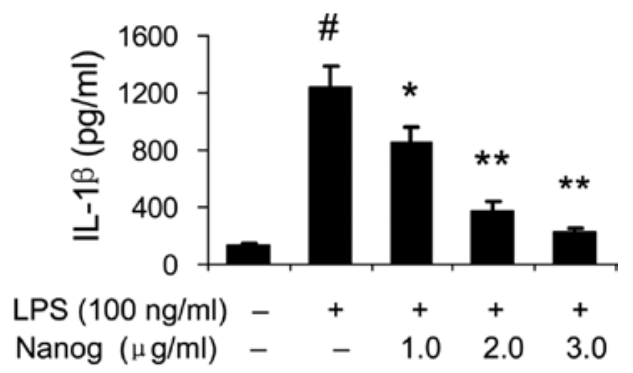

B

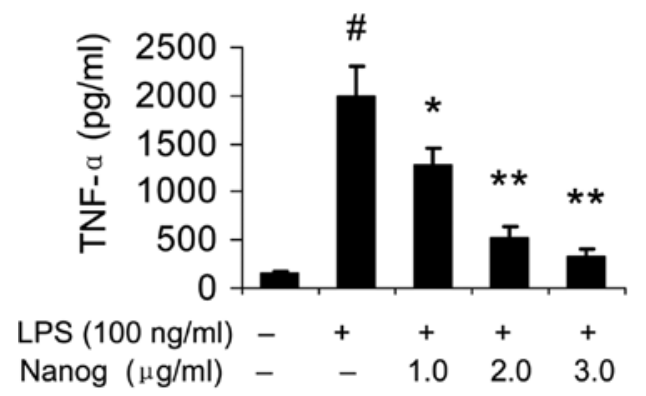

C

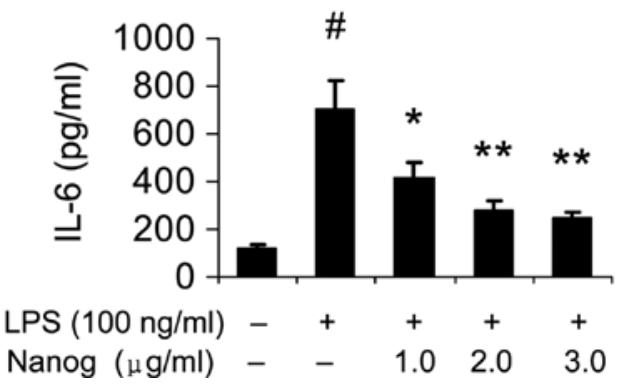

Figure 3. Effects of Nanog on the expression of IL-1 $1 \beta$, TNF- $\alpha$ and IL-6 in LPS-stimulated microglial cells at protein level. After being transfected with $0-3.0 \mu \mathrm{g} / \mathrm{ml} \mathrm{pCMV-Nanog}$ for $24 \mathrm{~h}$, cells were stimulated with LPS $(100 \mathrm{ng} / \mathrm{ml}$ ) for $24 \mathrm{~h}$. Cytokine levels for (A) IL-1 $\beta$, (B) TNF- $\alpha$ and (C) IL-6 in the culture supernatants were then measured using ELISA. All data are presented as the means $\pm \mathrm{SD}$ of three independent experiments. ${ }^{*} \mathrm{P}<0.01$ vs. the control group; ${ }^{*} \mathrm{P}<0.05,{ }^{* *} \mathrm{P}<0.01$ vs. the LPS-only treated group.

transcription factor binding to the promoter region of various genes, including pro-inflammatory cytokines and proteases (14). To understand the mechanism of Nanog-mediated inhibition of LPS-induced expression of pro-inflammatory cytokines, microglial cells were transfected with pNF-кB-luc, pRL-TK and different concentrations of pCMV-Nanog for $24 \mathrm{~h}$ and stimulated with LPS. Following $18 \mathrm{~h}$ of LPS stimulation, the activity of firefly luciferase and Renilla luciferase in the cells was estimated using luciferase assay. As shown in Fig. 4, LPS markedly increased the transcriptional activity of $\mathrm{NF}-\mathrm{\kappa B}$ in microglial cells, while the activity was significantly reduced by Nanog at different concentrations. These results suggest that Nanog may suppress LPS-induced expression of pro-inflammatory cytokines through the inhibition of transcriptional activity of NF- $\kappa B$.

\section{Discussion}

In the present study, we found for the first time that Nanog inhibits the expression of pro-inflammatory mediators IL-1 $\beta$,

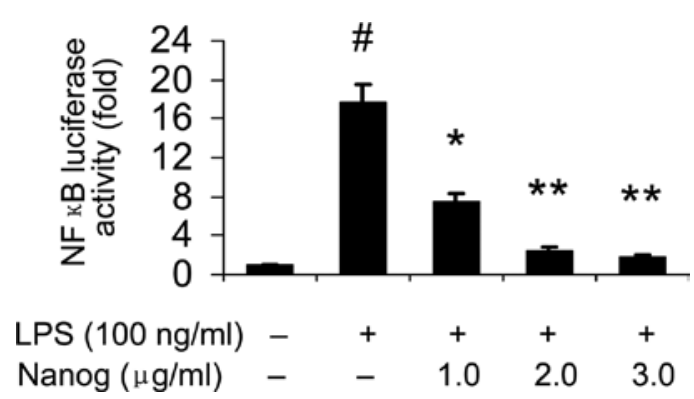

Figure 4. Effects of Nanog on the transcriptional activity of NF- $\kappa$ B in LPSstimulated microglial cells. After being transfected with $0.3 \mu \mathrm{g}$ pNF- $\kappa \mathrm{B}-\mathrm{luc}$ and $0.1 \mu \mathrm{g}$ pRL-TK, plus 0-3.0 $\mu \mathrm{g} / \mathrm{ml} \mathrm{pCMV}-\mathrm{Nanog}$ for $24 \mathrm{~h}$, cells were stimulated with LPS $(100 \mathrm{ng} / \mathrm{ml})$ for $18 \mathrm{~h}$. The transcriptional activity of $\mathrm{NF}-\kappa \mathrm{B}$ was then measured using the luciferase assay. All data are presented as the means $\pm \mathrm{SD}$ of three independent experiments. ${ }^{\#} \mathrm{P}<0.01$ vs. the control group; ${ }^{*} \mathrm{P}<0.05,{ }^{* *} \mathrm{P}<0.01$ vs. the LPS-only treated group.

TNF- $\alpha$ and IL- 6 in LPS-stimulated rat primary microglial cells by blocking the transcriptional activity of NF- $\mathrm{\kappa B}$.

Activated microglia is a characteristic feature of many neuroinflammatory disorders and it represents an attractive therapeutic target (15). Generally, an acute neuroinflammatory response is beneficial to the CNS as it helps to repair damaged tissue and to minimize further injury. However, chronic neuroinflammation is an often self-perpetuating response that persists long after an initial toxic insult and triggers abnormal brain functions $(16,17)$. The sustained release of inflammatory factors may perpetuate the neuroinflammatory process by activating additional glial cells, mainly microglia, which causes further release of pro-inflammatory and neurotoxic factors, contributing to neuronal dysfunction and consequently to pathology $(16,18)$. In response to injury, ischemia and inflammatory stimuli, microglial cells produce inflammatory cytokines, mainly including IL- $1 \beta$, TNF- $\alpha$ and IL- 6 (19). They are involved in all types of CNS injury and disease (17). In our study, Nanog significantly reduced the expression of IL-1 $\beta$, TNF- $\alpha$ and IL- 6 at the mRNA and proteins levels in LPS-stimulated microglial cells. These results suggest that Nanog may have anti-inflammatory properties in LPS-stimulated microglial cells.

The results also showed that suppression of the NF- $\mathrm{kB}$ transcriptional activity by Nanog may be the underlying mechanism in the reduction of pro-inflammatory mediators. $\mathrm{NF}-\mathrm{\kappa B}$ is a key transcription factor and plays an important role in immune responses, inflammatory diseases and cell death (14). In resting cells, NF- $\mathrm{kB}$ proteins are predominantly cytoplasmic, associating with inhibitor of NF- $\mathrm{kB}$ (IкB) (20). $\mathrm{NF}-\kappa \mathrm{B}$ activation is controlled by I $\kappa \mathrm{B}$ kinases (IKK) needed for phosphorylation-induced degradation of IкB (21). Upon activation by a variety of stimuli, such as cytokines and bacterial LPS, I $\mathrm{KB}$ is phosphorylated by IKK, subsequently ubiquitinylated and degraded by a proteasome complex. The liberated NF- $\mathrm{kB}$ then translocates to the nucleus and binds to its cognate DNA binding site in the promoter regions of various genes, including IL- $1 \beta$, TNF- $\alpha$ and IL- 6 , thereby leading to their transcription (22). Consistent with that study, we also found that Nanog inhibits the transcriptional activity of NF- $\mathrm{kB}$ in LPS-stimulated microglial cells, which was measured using luciferase assay. These results suggest that 
Nanog produces anti-inflammatory action through inhibition of NF- $\kappa \mathrm{B}$ transcriptional activity.

The present study has some limitations and questions which need to be examined further, such as the fact that Nanog only showed anti-inflammatory effect in vitro, while it is necessary to also confirm the results in vivo. Second, as an ES cell self-renewal gene, Nanog has been shown to be expressed in several tumor types and to regulate tumor development $(23,24)$. Notably, numerous studies have shown that NF- $\kappa \mathrm{B}$ is activated in various types of cancer cells and inhibition of $\mathrm{NF}-\kappa \mathrm{B}$ contributes to cancer treatment (25-27). Moreover, genes that are developmentally down-regulated may provide targets for future gene transfer studies to injured neurons $(28,29)$. Therefore, deleterious or protective actions produced by Nanog need to be investigated further.

In conclusion, the present study suggests that Nanog suppresses the release of pro-inflammatory mediators IL-1 $\beta$, TNF- $\alpha$ and IL- 6 in LPS-stimulated primary microglial cells. Anti-inflammatory effects of Nanog are associated with inhibition of the transcriptional activity of $N F-\kappa B$. Although further research is required to verify whether Nanog exhibits an antiinflammatory effect in vivo using animal model, these results suggest that Nanog may be a potentially useful anti-inflammatory therapy for the treatment of various nervous system diseases induced by uncontrolled activation of microglial cells.

\section{Acknowledgements}

This study was supported by grants from the Natural Science Foundation of Fujian Province (C0540003).

\section{References}

1. Graeber MB: Changing face of microglia. Science 330: 783-788, 2010.

2. Burguillos MA, Deierborg T, Kavanagh E, et al: Caspase signalling controls microglia activation and neurotoxicity. Nature 472: 319-324, 2011

3. Block ML, Zecca L and Hong JS: Microglia-mediated neurotoxicity: uncovering the molecular mechanisms. Nat Rev Neurosci 8 : 57-69, 2007.

4. Mitsui K, Tokuzawa Y, Itoh H, et al: The homeoprotein Nanog is required for maintenance of pluripotency in mouse epiblast and ES cells. Cell 113: 631-642, 2003.

5. Chambers I, Colby D, Robertson M, et al: Functional expression cloning of Nanog, a pluripotency sustaining factor in embryonic stem cells. Cell 113: 643-655, 2003.

6. Silva J, Nichols J, Theunissen TW, et al: Nanog is the gateway to the pluripotent ground state. Cell 138: 722-737, 2009.

7. Yu J, Vodyanik MA, Smuga-Otto K, et al: Induced pluripotent stem cell lines derived from human somatic cells. Science 318: 1917-1920, 2007.

8. Torres J and Watt FM: Nanog maintains pluripotency of mouse embryonic stem cells by inhibiting NFkappaB and cooperating with Stat3. Nat Cell Biol 10: 194-201, 2008.
9. Widera D, Mikenberg I, Kaltschmidt B and Kaltschmidt C: Potential role of NF-kappaB in adult neural stem cells: the underrated steersman? Int J Dev Neurosci 24: 91-102, 2006.

10. Lee EJ, Chen HY, Hung YC, et al: Therapeutic window for cinnamophilin following oxygen-glucose deprivation and transient focal cerebral ischemia. Exp Neurol 217: 74-83, 2009.

11. Keene CD, Chang R, Stephen C, et al: Protection of hippocampal neurogenesis from toll-like receptor 4-dependent innate immune activation by ablation of prostaglandin E2 receptor subtype EP1 or EP2. Am J Pathol 174: 2300-2309, 2009.

12. Morales I, Farias G and Maccioni RB: Neuroimmunomodulation in the pathogenesis of Alzheimer's disease. Neuroimmunomodulation 17: 202-204, 2010.

13. Yokoyama H, Uchida H, Kuroiwa H, Kasahara J and Araki T: Role of glial cells in neurotoxin-induced animal models of Parkinson's disease. Neurol Sci 32: 1-7, 2011.

14. Niederberger E and Geisslinger G: The IKK-NF-kappaB pathway: a source for novel molecular drug targets in pain therapy? FASEB J 22: 3432-3442, 2008.

15. Bajramovic JJ: Regulation of innate immune responses in the central nervous system. CNS Neurol Disord Drug Targets 10: 4-24, 2011.

16. Agostinho P, Cunha RA and Oliveira C: Neuroinflammation, oxidative stress and the pathogenesis of Alzheimer's disease. Curr Pharm Des 16: 2766-2778, 2010.

17. Lucas SM, Rothwell NJ and Gibson RM: The role of inflammation in CNS injury and disease. Br J Pharmacol 147 (Suppl 1): 232-240, 2006

18. Harry GJ and Kraft AD: Neuroinflammation and microglia: considerations and approaches for neurotoxicity assessment. Expert Opin Drug Metab Toxicol 4: 1265-1277, 2008.

19. Garden GA and Moller T: Microglia biology in health and disease. J Neuroimmune Pharmacol 1: 127-137, 2006.

20. Moynagh PN: The NF-kappaB pathway. J Cell Sci 118: 4589-4592, 2005

21. Rius J, Guma M, Schachtrup C, et al: NF-kappaB links innate immunity to the hypoxic response through transcriptional regulation of HIF-1alpha. Nature 453: 807-811, 2008.

22. Ha SK, Moon E and Kim SY: Chrysin suppresses LPS-stimulated proinflammatory responses by blocking NF-kappaB and JNK activations in microglia cells. Neurosci Lett 485: 143-147, 2010.

23. Zhou X, Zhou YP, Huang GR, et al: Expression of the stem cell marker, Nanog, in human endometrial adenocarcinoma. Int J Gynecol Pathol 30: 262-270, 2011.

24. Jeter CR, Liu B, Liu X, et al: NANOG promotes cancer stem cell characteristics and prostate cancer resistance to androgen deprivation. Oncogene 30: 3833-3845, 2011

25. Noh EM, Lee YR, Hur H and Kim JS: Radix clematidis extract inhibits TPA-induced MMP-9 expression by suppressing NF-kappaB activation in MCF-7 human breast cancer cells. Mol Med Rep 4: 879-883, 2011.

26. Maeda S, Hikiba Y, Sakamoto K, et al: Colon cancer-derived factors activate NF-kappaB in myeloid cells via TLR2 to link inflammation and tumorigenesis. Mol Med Rep 4: 1083-1088, 2011.

27. Liu A, Chen $\mathrm{H}$, Tong $\mathrm{H}$, et al: Emodin potentiates the antitumor effects of gemcitabine in pancreatic cancer cells via inhibition of nuclear factor-kappaB. Mol Med Rep 4: 221-227, 2011.

28. Franz S, Weidner N and Blesch A: Gene therapy approaches to enhancing plasticity and regeneration after spinal cord injury. Exp Neurol: Jan, 2011 (E-pub ahead of print).

29. Moore DL, Blackmore MG, Hu Y, et al: KLF family members regulate intrinsic axon regeneration ability. Science 326: 298-301, 2009. 